This document is confidential and is proprietary to the American Chemical Society and its authors. Do not copy or disclose without written permission. If you have received this item in error, notify the sender and delete all copies.

\title{
Removal of antibiotic-resistant bacteria and antibiotic resistance genes affected by varying degrees of fouling on anaerobic microfiltration membranes
}

\begin{tabular}{|r|l|}
\hline Journal: & Environmental Science \& Technology \\
\hline Manuscript ID & es-2017-03798u.R1 \\
\hline Manuscript Type: & Article \\
\hline Date Submitted by the Author: & $\mathrm{n} / \mathrm{a}$ \\
\hline Complete List of Authors: & $\begin{array}{l}\text { Cheng, Hong; King Abdullah University of Science and Technology } \\
\text { Hong, Peiying; King Abdullah University of Science and Technology, } \\
\text { Biological and Environmental Science and Engineering }\end{array}$ \\
\hline
\end{tabular}


New membrane

\section{Increase in fouling severity}
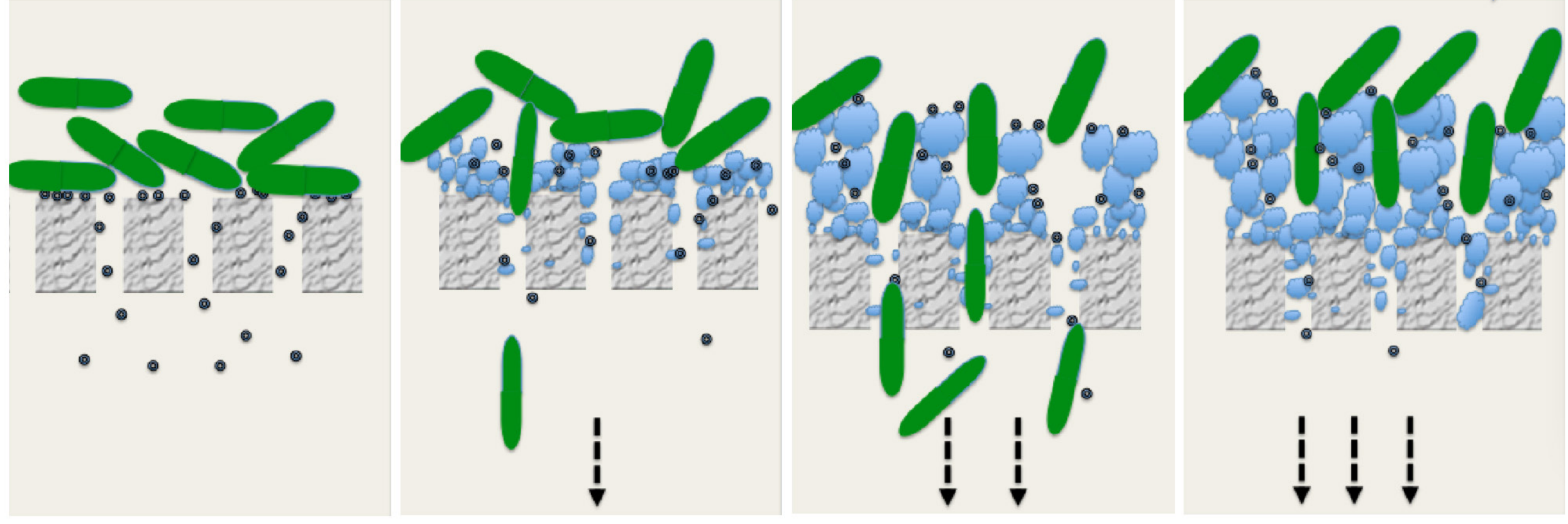

- Plasmid

Bacterium

I Driving force 
1 Removal of antibiotic-resistant bacteria and antibiotic resistance genes

2 affected by varying degrees of fouling on anaerobic microfiltration

\section{membranes}

5 §King Abdullah University of Science and Technology (KAUST), Division of Biological

6 and Environmental Science \& Engineering (BESE), Water Desalination and Reuse

7 Center (WDRC), Thuwal, 23955-6900, Saudi Arabia

$21 *$ Corresponding author:

22 Pei-Ying Hong

23 Email: peiying.hong@kaust.edu.sa

24 Phone: +966-12-8082218

26 Keywords: Anaerobic membrane bioreactor, extended-spectrum beta-lactamase,

27 biofouling, transmembrane pressure

28 Running title: Removal of ARB and ARGs by anaerobic membranes 


\section{ABSTRACT}

30 An anaerobic membrane bioreactor was retrofitted with polyvinylidene fluoride (PVDF)

31 microfiltration membrane units, each of which was fouled to a different extent. The

32 membranes with different degrees of fouling were evaluated for their efficiencies in

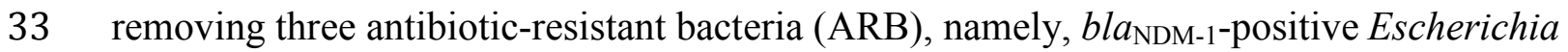

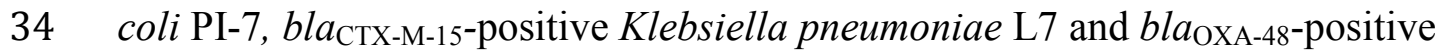

35 Escherichia coli UPEC-RIY-4, as well as their associated plasmid-borne antibiotic

36 resistance genes (ARGs). The results showed that the log removal values (LRVs) of

37 ARGs correlated positively with the extent of membrane fouling and ranged from 1.9 to

38 3.9. New membranes with a minimal foulant layer could remove more than 5-log units of

39 ARB. However, as the membranes progressed to subcritical fouling, the LRVs of ARB

40 decreased at increasing operating transmembrane pressures (TMPs). The LRV recovered

41 back to 5 when the membrane was critically fouled, and the achieved LRV remained

42 stable at different operating TMPs. Furthermore, characterization of the surface attributed

43 the removal of both the ARB and ARGs to adsorption, which was facilitated by an

44 increasing hydrophobicity and a decreasing surface zeta potential as the membranes

45 fouled. Our results indicate that both the TMP and the foulant layer synergistically

46 affected ARB removal, but the foulant layer was the main factor that contributed to ARG

47 removal. 


\section{1. INTRODUCTION}

52 Municipal wastewater treatment plants have been identified as hotspots for the

53 enrichment of antibiotic-resistant bacteria (ARB) and antibiotic resistance genes (ARGs)

54 and can potentially contribute to the dissemination of ARB and ARGs into the

55 environment ${ }^{1-3}$. In contrast to secondary biological activated sludge processes, which are

56 unable to achieve good removal efficiencies for ARB and ARGs ${ }^{4,5}$, aerobic membrane

57 bioreactors (aeMBRs) were reported in prior studies to achieve $>5.5$-log removal of

58 bacteria $^{6,7}$ and $>2.67-\log$ removal of ARGs ${ }^{8}$. However, operating an aeMBR would

59 require high energy consumption rates, and that process produces waste sludge that is

60 viewed as a hotbed for ARB and ARGs ${ }^{1}$. A relatively more sustainable alternative to an

61 aeMBR would be an anaerobic membrane bioreactor (anMBR). An anMBR couples a

62 membrane-based filtration process with anaerobic fermentation, which would not only

63 eliminate the need for aeration but also generate methane as an energy source.

64 Furthermore, anaerobic fermentation has lower sludge production rates compared to

65 activated sludge processes ${ }^{9}$.

66

67 Despite the advantages of anMBRs compared to aeMBRs, the main drawback for both

68 technologies is membrane biofouling. Biofouling causes a decrease in water flux and

69 higher energy consumption rates and operational costs ${ }^{10}$. Even though several

70 approaches have been developed to alleviate the biofouling of membranes (e.g.,

71 backwash, chemical wash, and sonication) ${ }^{11}$, the total eradication of the foulant layer is

72 not possible. Therefore, a conventional norm that subcritically fouled membranes remain

73 in operation as long as their flux is not compromised exists. Its existence means that 
74 membranes have an additional foulant layer that has been shown to improve the rejection

75 of bacterial cells and that cleaning the membrane to remove the foulant layer would lead

76 to a reduction of 1 in the $\log$ removal values (LRVs) for the bacterial cells in an aeMBR

$7{ }^{12}$. The mechanism by which fouled membranes retain particles in wastewater results

78 from many factors (e.g., surface characteristics and pore blockage) ${ }^{13-15}$. To illustrate,

79 Cho et al. reported that steric exclusion and aromatic/hydrophobic and charge interactions

80 affect the removal efficiency of natural organic matter ${ }^{13}$. In addition, pore blockage by a

81 cake layer also served to increase the number of retained particles ${ }^{14,15}$.

82

83 Earlier studies have reported an approximately 3 to 6-log removal of bacteria in aeMBRs

$84 \quad 6,7,12$. However, with increased fouling, the transmembrane pressure (TMP)

85 concomitantly rises during the operation, and the operating pressure to drive water

86 through the membrane must increase to maintain a constant flux. Therefore, an increase

87 in the TMP at constant flux may affect the membrane rejection rates. Specifically, this

88 study hypothesizes that an increase in the operating filtration pressure may compromise

89 the LRV for ARB achieved by fouled membranes. This hypothesis has not been

90 systematically assessed in most studies, particularly those that evaluate the performance

91 of anMBRs.

92

93 Furthermore, several differences exist between the aerobic and anaerobic foulant layers.

94 To illustrate, Xiong et al. studied the foulant layers attached to membranes connected to 95 aerobic and anaerobic membrane bioreactors of the same reactor configuration ${ }^{16}$. Their

96 findings suggest that when both membrane bioreactors were operated under similar 
97 conditions, differences occurred in the characteristics of both the aerobic and anaerobic

98 foulant layers, specifically in both the concentration and molecular weight of not only the

99 extracellular polymeric substances (EPS) but also the soluble microbial products (SMP).

100 In addition, Yun et al. proved that the anoxic cake layer was more uniform compared to

101 the aerobic one ${ }^{17}$. These differences may mean that the LRVs previously reported for

102 aeMBR systems may not be representative of anMBR systems. As anMBRs are

103 increasingly under consideration for municipal wastewater treatment, differences in their

104 foulant layers compared with those of aeMBRs suggest the existence of a knowledge gap

105 regarding their ability to remove ARB and ARGs.

107 In the present study, we evaluated the removal efficiency for ARBs and ARGs achieved

108 by anaerobic microfiltration (MF) membranes that were fouled to varying degrees (i.e.,

109 N0: new membrane; F1: membrane harvested at $\sim 20 \mathrm{kPa} ; \mathrm{F} 2$ : membrane harvested at $\sim 40$

$110 \mathrm{kPa}$; and F3: membrane harvested at $\sim 60 \mathrm{kPa}$ ). Three types of pathogenic ARB (i.e., $E$.

111 coli PI-7, K. pneumoniae L7 and E. coli UPEC-RIY-4) and their associated plasmid-

112 borne ARGs (i.e., $b l a_{\mathrm{NDM}-1}, b l a_{\mathrm{CTX}-\mathrm{M}-15}$ and $b l a_{\text {OXA-48 }}$ ) were applied as model

113 contaminants. The genes $b l a_{\mathrm{NDM}-1}, b l a_{\mathrm{CTX}-\mathrm{M}-15}$ and $b l a_{\mathrm{OXA}-48}$ code for carbapenemases and

114 extended-spectrum beta-lactamases, which are enzymes that confer resistance to

115 carbapenems and other beta-lactam antibiotics. Carbapenems compose a new class of

116 beta-lactam antibiotics that are typically used as a last-resort treatment against gram-

117 negative bacterial infections. The ARB that are resistant as well as the ARGs that confer

118 resistance to such antibiotics are listed as global concerns by the World Health

119 Organization (http://www.who.int/mediacentre/news/releases/2017/bacteria-antibiotics- 
120 needed/en/). These ARB and ARGs were therefore used to determine whether anaerobic

121 membrane bioreactors have the capability of removing these contaminants from

122 wastewaters. Specifically, the aims of this study are to elucidate whether the fouling of

123 anaerobic membranes to varying degrees affects the removal efficiency of biological,

124 emerging contaminants (i.e., ARGs and ARB) and whether the removal rates vary when a

125 fouled membrane is subjected to different operating pressures.

\section{MATERIAL AND METHODS}

129 2.1. Reactor configuration and operating conditions. The anMBR operated in this

130 study followed the same configuration (Figure S1A) as that operated in an earlier study

$131{ }^{16}$. Briefly, the reactor was fed with synthetic wastewater having a chemical oxygen

132 demand (COD) of $750 \mathrm{mg} / \mathrm{L}$ and operated at $35^{\circ} \mathrm{C}$ and a $\mathrm{pH}$ of 7 . Two separate runs

133 were conducted (i.e., Run 1 and Run 2), spaced approximately 4 months apart. For each

134 run, three PVDF microfiltration (MF) membranes (GE Osmonics, Minnetonka, MN,

135 USA) that were individually housed in cassette holders were connected in parallel to the

136 anaerobic reactor. The membranes had a nominal pore size of $0.3 \mu \mathrm{m}$. The anMBR was

137 operated at a $300 \mathrm{~mL} / \mathrm{min}$ recirculation rate. Biogas was used to scour the membrane

138 surface at a gas sparging rate of $100 \mathrm{~mL} / \mathrm{min}$. The flux was maintained at approximately

$1397 \mathrm{~L} / \mathrm{m}^{2} / \mathrm{h}(\mathrm{LMH})$, while the changes in TMP were recorded by a pressure gauge

140 connected to each membrane module (Figure S2). The COD of the effluent was

141 quantified weekly. 
143 2.2. Membrane characterization. An FEI Nova Nano scanning electron microscope

144 (SEM) was used to characterize a cross section of the cake layer at $5 \mathrm{kV}$. In preparation

145 for the SEM examination, membrane samples with dimensions of 1 by $2.5 \mathrm{~cm}$ were air-

146 dried and then each affixed to an aluminum stub. Iridium was sputtered at a thickness of

$1473 \mathrm{~nm}$ onto the membrane surface with a K575X Emitech sputter coater (Quorum

148 Technologies, UK). Atomic force microscopy (AFM) was used to characterize the

149 membrane surface topography. The air-dried membranes were first attached to a support

150 plate and then imaged by an Agilent 5500 AFM system (Agilent Technologies Inc., Palo

151 Alto, CA, USA) in contact mode. Silicon cantilevers (Applied NanoStructures, Inc.; CA;

152 USA) with a resonance frequency of $11-19 \mathrm{kHz}$ and a force constant of $0.1-0.6 \mathrm{Nm}^{-1}$

153 were used. The acquired AFM images were post-processed by Gwyddion software. For

154 each membrane, five random $10 \times 10 \mu \mathrm{m}$ square pictures were scanned. The contact

155 angle was measured by an EasyDrop shape analyzer (Krüss, Hamburg, Germany) in

156 static mode at ambient temperature to evaluate whether the membranes were hydrophilic

$157\left(<90^{\circ}\right)$ or hydrophobic $\left(>90^{\circ}\right)$. Ultrapure water was used as the probing liquid, and the

158 mean values were determined from five different independent specimens. The surface

159 zeta potential was measured in a Nano Zetasizer surface cell cuvette containing trace

160 particles (Nano ZS Zen3600, Malvern, UK) at pH 7 and $25^{\circ} \mathrm{C}$, as described elsewhere ${ }^{18}$.

161 The membranes to be measured were placed inside the cell cuvette, and the surface zeta

162 potential was evaluated by measuring the zeta potentials of the tracer particles at different

163 distances from the membrane surface. A linear change with distance is observed, and the

164 value at a distance equal to zero is extrapolated automatically by the instrument. 


\subsection{Determination of polysaccharides (PS) and proteins (PN) in soluble}

167 extracellular polymeric substances (EPS). The PS and PN concentrations in the soluble

168 EPS fraction from fouled membranes were quantified based on the modified protocols

169 specified by an earlier study ${ }^{19}$. Briefly, the membranes were harvested, placed in $30 \mathrm{~mL}$

170 of sterile 1X M9 minimal salt medium and then vortexed at maximum speed for 2 min to

171 detach the biofilm from the membrane. A $10 \mathrm{~mL}$ aliquot of suspension was centrifuged at

$17210,000 \times \mathrm{g}$ for $10 \mathrm{~min}$, and the supernatant was filtered through a $0.22-\mu \mathrm{m}$ syringe filter

173 (VWR US, Radnor, PA, USA) before its PS and PN contents were determined. The PSs

174 were determined in triplicate for each sample by the phenol-sulfuric acid method. The

175 PNs were quantified in triplicate by a Total Protein Kit (Sigma-Aldrich, St. Louis, MO,

176 USA).

177

178 2.4. Filtration experiment for ARB. The MF membranes enclosed in their cassette

179 modules were harvested for the filtration experiments at the TMPs of $\sim 20 \mathrm{kPa}, \sim 40 \mathrm{kPa}$

180 and $\sim 60 \mathrm{kPa}$ (hereafter named F1, F2 and F3, respectively) (Figure S1B). The membranes

181 harvested at $\sim 20 \mathrm{kPa}$ and $\sim 40 \mathrm{kPa}$ represent subcritically fouled membranes having an

182 increase in the foulant layer corresponding to the TMP level. The membranes harvested

183 at $\sim 60 \mathrm{kPa}$ correspond to critically fouled membranes. The definition for subcritically

184 fouled and critically fouled membranes was made based on the slope of the relationship

185 between the TMP profile and the duration (Figure S2). The subcritically fouled

186 membranes were defined as those with a TMP that increased at an exponential rate to

187 maintain a constant flux (ca. 7 LMH). The critically fouled membranes were defined as

188 those with TMP that reached a plateau and were no longer capable of further increases to 
189 maintain a constant flux. Three types of ARB, namely, bla NDM-1-positive E. coli PI-7 $^{20}$

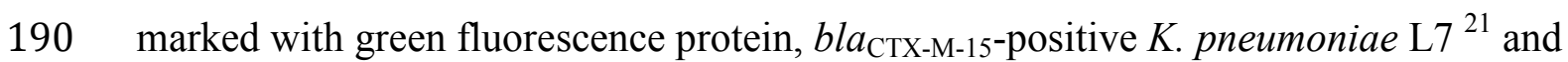

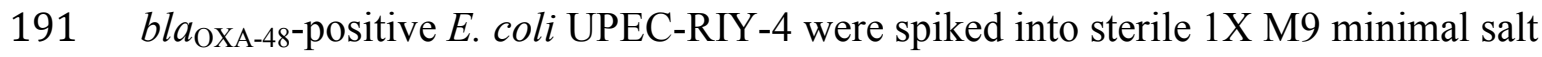

192 medium (Sigma-Aldrich, St. Louis, MO, USA) to obtain a final $\mathrm{OD}_{600}$ of $\sim 0.3$. The

193 growth conditions for each ARB are provided in Supplementary Material S1. The culture

194 suspension with bacteria was independently filtered through the F1, F2 and F3

195 membranes. The same culture suspensions were also filtered through new membranes.

196 All the filtration experiments were operated at a recirculation rate of $300 \mathrm{~mL} / \mathrm{min}$ and a

197 nitrogen sparging rate of $100 \mathrm{~mL} / \mathrm{min}$ to approximate the same conditions experienced in 198 the anMBR.

199 During the filtration experiment, the filtration TMP was incrementally adjusted for F1, F2 200 and F3 to determine whether an increase in filtration pressure would affect the removal 201 efficiencies achieved by each type of fouled membrane. The permeate was sampled every $2024 \mathrm{~h}$ prior to increasing the filtration TMP. For example, the filtration TMP for F1 was 203 incrementally increased from $5 \mathrm{kPa}$ to $10 \mathrm{kPa}$, then to $15 \mathrm{kPa}$ and finally to $20 \mathrm{kPa}$ (the 204 permeates collected at each TMP are hereafter referred to as F1-1, F1-2, F1-3 and F1-4, 205 respectively). Similarly, for F2, the TMP was incrementally adjusted from $10 \mathrm{kPa}$ to 20 $206 \mathrm{kPa}, 30 \mathrm{kPa}$ and finally $40 \mathrm{kPa}$ (the permeates collected at each TMP are hereafter 207 referred as F2-1, F2-2, F2-3 and F2-4, respectively). For F3, the filtration TMP was 208 increased from $10 \mathrm{kPa}$ to $20 \mathrm{kPa}, 40 \mathrm{kPa}$ and $60 \mathrm{kPa}$ sequentially (the permeates collected 209 at each TMP are hereafter referred as F3-1, F3-2, F3-3 and F3-4, respectively) (Table S1).

210 The filtration experiment with the new membrane was performed at fluxes matching

211 those of the F1 membranes. In all instances, no filtration TMP was observed with the new 
212 membrane since no foulant layer existed. The permeate was collected at the same

213 abovementioned intervals to provide corresponding controls, and these permeates are

214 hereafter referred as N0-1, N0-2, N0-3 and N0-4, respectively. Table S1 summarizes the

215 matrix of conditions used in this study. At the end of the filtration experiments, all the

216 membranes were harvested for characterization, as detailed in section 2.3. The biofilm

217 attached to the membranes and the permeate were processed and extracted for their total

218 DNA, as previously described ${ }^{19}$.

220 2.5. Filtration experiment for ARGs. A $60 \mathrm{~mL}$ sample of each bacterial host was

221 incubated in a $200 \mathrm{rpm}$ shaker incubator for $17 \mathrm{~h}$ at $37^{\circ} \mathrm{C}$ and then extracted for its

222 plasmids by the PureYield ${ }^{\mathrm{TM}}$ Plasmid Miniprep System (Promega, Madison, WI, USA).

223 Earlier work sequenced the bla $_{\mathrm{NDM}-1}$-positive plasmid ${ }^{3}$, and the associated plasmid size

224 was known. In addition, the present study sequenced the $b l a_{\mathrm{CTX}-\mathrm{M}-15-\text { positive plasmid }}$

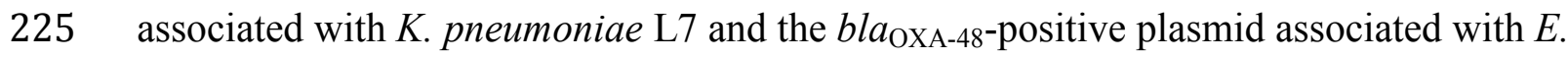

226 coli UPEC-RIY-4 via the Illumina MiSeq platform (Illumina, San Diego, CA, USA). The

227 specific protocols detailing the sequencing and assembly are provided in Supplementary

228 Material S2. The plasmids were spiked into sterile 1X M9 minimal salt medium to a final

229 concentration of $\sim 10^{5}$ copies/mL. The filtration experiment for the ARGs was conducted

230 in a manner similar to that described in section 2.4 but without the increments in the

231 filtration TMP. After the filtration experiment, the membranes were harvested for

232 characterization, as detailed in section 2.3. Six milliliters of each biomass suspension and

233 permeate were frozen at $-80{ }^{\circ} \mathrm{C}$ and lyophilized using a Christ Alpha 1-2 LDplus freeze 
234 dryer. The lyophilized biomass suspension and permeate were subjected to DNA

235 extraction, as previously described ${ }^{22}$.

236

237 2.6. Quantification of ARB and ARGs. The ARB were quantified by determining their

238 associated ARG marker. The quantification of the associated ARGs (i.e., bla $a_{\mathrm{NDM}-1}$,

$239 b l a_{\text {CTX-M-15 }}$ and $b l a_{\text {OXA-48 }}$ ) was conducted with an Applied Biosystems 7900 HT Fast Real-

240 Time PCR (qPCR) System (Thermo Fisher Scientific, Carlsbad, CA, USA). The TaqMan

241 probes and corresponding primer sequences are listed in Table S2. The qPCR standards

242 for the associated genes were prepared as described previously ${ }^{23}$. The thermal cycle and

243 detection limit are shown in Supplementary Material S3. In addition, to verify the qPCR

244 result, flow cytometry by the BD FACSCanto II system ((BD Biosciences, San Jose, CA,

245 USA) was used to determine the cell counts of the bla $a_{\mathrm{NDM}-1}$-positive $E$. coli $\mathrm{PI}-7$, based

246 on the green fluorescence protein.

248 2.7. ARB adsorption comparison. To compare adsorption between the ARB and the

249 foulant layer, isothermal titration calorimetry (ITC) was applied (Malvern ITC200,

250 Malvern, UK). ITC measures the heat change that occurs when two substances interact. $E$.

251 coli PI-7, K. pneumoniae L7 and E. coli UPEC-RIY-4 were respectively incubated in a

$252200 \mathrm{rpm}$ shaker incubator for $17 \mathrm{~h}$ at $37^{\circ} \mathrm{C}$ and then centrifuged at $10,000 \mathrm{~g}$ for $10 \mathrm{~min}$ to

253 obtain cell pellets. The cell pellets were resuspended and washed twice with M9 minimal

254 salt medium and recentrifuged before the washed pellets were finally resuspended in M9

255 minimal salt medium and diluted to a final $\mathrm{OD}_{600}$ of 0.3 . Ten milliliters of the different

256 foulant suspensions from section 2.3 was filtered through $40 \mu \mathrm{m}$ Falcon ${ }^{\mathrm{TM}}$ Cell Strainers 
257 (Fisher Scientific, USA). The filtrate was respectively aliquoted and then diluted 1:4 v/v

258 in M9 minimal salt medium. Two microliters of the filtrate was injected into $200 \mu \mathrm{L}$ of

259 each ARB suspension at $25^{\circ} \mathrm{C}$ using a $750 \mathrm{rpm}$ stirring speed and $4 \mathrm{~s}$ duration. Each

260 sample was injected into the ITC machine a total of 12 times, with a $120 \mathrm{~s}$ interval

261 between each injection. The resulting values were analyzed and plotted using Origin

262 (version 7).

263

264 2.8. Statistical analysis. Significance was analyzed either by a two-tailed t-test, available

265 in Microsoft Excel 2013, or by one-way ANOVA, available in Minitab Express.

268 3. RESULTS

269 3.1. Differences in the thickness and the PS and PN concentrations of F1, F2 and F3

270 membranes. As fouling progressed from F1 to F3, the thickness of the foulant layer, as

271 evidenced from the cross-sectional images of the membranes, revealed a corresponding

272 increase (Figure S3). Its thickness for F1 was approximately $2.99 \pm 0.17 \mu \mathrm{m}$ in Run 1 and

$2733.96 \pm 0.26 \mu \mathrm{m}$ in Run 2 (Table 1). When the TMP increased to $\sim 40 \mathrm{kPa}$ (i.e., F2), the

274 foulant layer thickness increased by $>2$ times compared to that for F1 $(8.80 \pm 0.13 \mu \mathrm{m}$ in

275 Run 1 and $10.43 \pm 0.48 \mu \mathrm{m}$ in Run 2). F3, the critically fouled membrane, had a foulant

276 layer thickness of $26.92 \pm 3.24 \mu \mathrm{m}$ in Run 1 and $20.33 \pm 0.43 \mu \mathrm{m}$ in Run 2 . The

277 estimated biovolume increased from F1 to F3 with the increasing thickness (Table 1).

278 The polysaccharide (PS) concentration increased significantly as fouling progressed (t-

279 test, $\mathrm{p}<0.01$ ), rising from 17.53 and $25.63 \mu \mathrm{g} / \mathrm{cm}^{2}$ in Run 1 and Run 2 , respectively, for 
$280 \mathrm{~F} 1$ to 73.89 and $45.18 \mu \mathrm{g} / \mathrm{cm}^{2}$ in Run 1 and Run 2 for F2. For F3, the PS concentration

281 further increased to 96.56 and $133.27 \mu \mathrm{g} / \mathrm{cm}^{2}$ in Run 1 and Run 2, respectively (Figures

282 S4A and S4C). Similarly, the protein (PN) concentration also increased significantly

283 from $\mathrm{F} 1$ to $\mathrm{F} 3$ (t-test, $\mathrm{p}<0.01$ ). The PN concentration in the foulant layer was 4.36 and

$2845.00 \mu \mathrm{g} / \mathrm{cm}^{2}$ in Run 1 and Run 2, respectively, for F1. These values increased for F3 to

28519.36 and $25.50 \mu \mathrm{g} / \mathrm{cm}^{2}$ in Run 1 and Run 2, respectively (Figures S4B and S4D).

287 3.2. Differences in the surface characteristics of F1, F2 and F3 membranes. Among

288 all the tested membranes, the new membrane (i.e., N0) had the roughest surface area $\left(\mathrm{R}_{\mathrm{a}}\right.$

$289=118.3 \pm 27.0$ ) and was significantly rougher than the three fouled membranes (i.e., F1,

290 F2 and F3) (t-test, p < 0.01) (Table 1). As the membranes fouled, the hydrophobicity of

291 the membrane surfaces increased (Table 1). The new PVDF membrane was hydrophilic

$292\left(78.7 \pm 3.8^{\circ}\right)$, but the presence of a foulant layer caused the contact angle to increase to

$29390.2 \pm 2.3^{\circ}$ for F1, indicating that the membrane surface became hydrophobic. The

294 contact angle further increased to $95.5 \pm 2.3^{\circ}$ and $107.4 \pm 1.6^{\circ}$ for $\mathrm{F} 2$ and F3, respectively.

295 In addition, the new membrane exhibited the lowest surface zeta potential (i.e., $-44.3 \pm$

$2964.4 \mathrm{mV}$ ) (Table 1). In contrast, the surface zeta potential values for the fouled membranes

297 were $-17.3 \pm 0.3 \mathrm{mV},-19.2 \pm 1.9 \mathrm{mV}$ and $-25.8 \pm 2.3 \mathrm{mV}$; these membranes showed a

298 significantly lower negative charge than that measured for the new membrane (t-test, $\mathrm{p}<$ $2990.01)$.

300

301 3.3. ARGs showed smaller particulate sizes but a higher negative charge compared

302 to ARB. The results obtained from the dynamic light scattering technique indicated that 
303 the average particulate size of E. coli PI-7, K. pneumoniae L7 and E. coli UPEC-RIY-4

304 was $1899.4 \pm 235.4 \mathrm{~nm}, 1956.2 \pm 253.0 \mathrm{~nm}$, and $2141 \pm 33.9 \mathrm{~nm}$, respectively. In

305 contrast, all of the three plasmids were smaller than $565 \mathrm{~nm}$ (Figure S5A). The zeta

306 potential assessments of plasmids showed that all three plasmids and the ARBs were

307 negatively charged. The absolute zeta potential value of plasmids was greater than 22

$308 \mathrm{mV}$; in contrast, the absolute charge of bacteria was always less than $15 \mathrm{mV}$ (Figure

309 S5B).

311 3.4. Increase in LRV for ARGs with fouling severity. In Run 1, the new membrane

312 achieved an LRV of 2.75 for the plasmid encoding the $b l a_{\mathrm{NDM}-1}$ gene. The LRVs achieved

313 by F1, F2 and F3 were higher, reaching 3.48, 3.60 and 3.84, respectively (Figure 1A). A

314 similar increment in the LRV was observed for the plasmid encoding the $b l a_{\text {OXA- } 48}$ gene.

315 To illustrate, the LRV achieved by the new membrane was 1.90, but this value increased

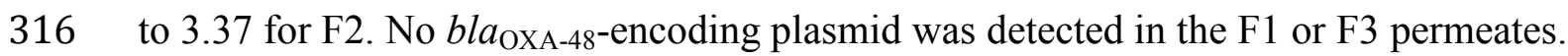

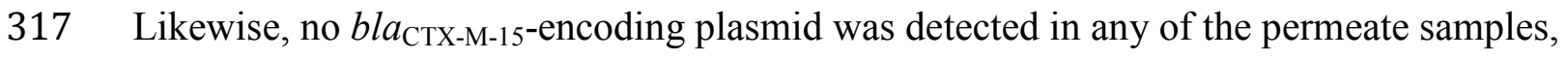

318 and no LRVs could be obtained.

319 To confirm that the LRVs of the ARG-encoding plasmids were higher in the presence of

320 fouled membranes, a replicate run was conducted. In Run 2, the LRVs achieved by new

321 membrane were $2.30,2.13$ and 2.42 for the plasmids encoding bla $_{\mathrm{NDM}-1}$, bla $_{\mathrm{CTX}-\mathrm{M}-15}$ and

$322 b l a_{\text {OXA-48, }}$, respectively (Figure 1C). In contrast, all the LRVs for the fouled membrane

323 were higher than 2.76, and the LRV increased as fouling progressed. The LRV of the

324 plasmid encoding bla $a_{\mathrm{NDM}-1}$ achieved by F1, F2 and F3 were 1.3-, 1.2- and 1.5-fold higher

325 than that achieved by the new membrane. Similarly, the LRV for the plasmid encoding 
326 bla $a_{\text {СТХ-M-15 }}$ increased to 3.35 and 3.45 on the F1 and F2 fouled membranes, and no

327 detectable bla $_{\mathrm{CTX}-\mathrm{M}-15}$ was present in the F3 permeate. In addition, the LRVs for the

328 plasmid encoding bla $a_{\mathrm{OXA}-48}$ were higher using the fouled membranes compared to the

329 new membrane (Figure 1C).

330

331 3.5. Foulant layer enhanced the adsorption of ARGs. The abundance of plasmids

332 encoding the $b l a_{\mathrm{NDM}-1}$ gene and attached to the new membrane was approximately $1.90 \mathrm{x}$

$33310^{3}$ and $5.51 \times 10^{2}$ copies $/ \mathrm{cm}^{2}$ in Run 1 and Run 2 , respectively. In contrast, the respective

334 abundance of these plasmids attached to the F1, F2 and F3 membranes increased to 2.61

$335 \times 10^{5}, 1.46 \times 10^{4}$ and $3.11 \times 10^{4}$ copies $/ \mathrm{cm}^{2}$ for Run 1 ; and these abundances were

336 significantly higher than that obtained for this plasmid using the new membrane (t-test, $p$

$337<0.01$ ) (Figure 1B). In Run 2, the abundances of the plasmid encoding bla $_{\mathrm{NDM}-1}$ and

338 attached to the fouled membranes were up to 74 times higher than the abundance of this

339 plasmid detected on the new membrane (Figure 1D). Similar trends were observed for the

340 other two plasmids (Figures 1B and 1D).

341

342 3.6. New membrane and critically fouled F3 membrane displayed high LRVs for

343 ARBs. The qPCR results indicated that new membrane can achieve a high LRV for all

344 the tested ARB. To illustrate, the average LRVs were 6.50, 6.50 and 5.39 in Run 1 for $E$.

345 coli PI-7, K. pneumoniae and E. coli UPEC-RIY-4, respectively. The same range of

346 LRVs was achieved in Run 2 (Figures 2A to 2C). In contrast, the average LRV achieved

347 by F1 for E. coli PI-7 decreased to 3.48 and 4.99 . The average LRV further decreased to

3481.28 and 2.18 in the two runs for E. coli PI-7 when a more heavily fouled F2 membrane 
349 was tested. However, the average LRV for the F3 treatment increased in both runs to

350 approximately that achieved by the new membranes (Figure 2A), and the LRVs obtained

351 for F3 and for the new membranes were not significantly different (one-way ANOVA, $\mathrm{p}>$

352 0.05). Specifically, the LRV for E. coli PI-7 was 5.19 in Run 1 and 4.51 in Run 2. These

353 LRVs achieved by F3 were, however, significantly higher than those achieved by F2

354 (one-way ANOVA, $\mathrm{p}<0.01$ ). The same trend was also observed for the average LRVs of

355 K. pneumoniae and E. coli UPEC-RIY-4 as the severity of membrane fouling progressed

356 (Figures 2B and 2C).

357 A further evaluation was undertaken to determine whether an increase in the filtration

358 pressure would affect the LRV achieved by membranes fouled to different degrees. For

359 the F1 and F2 subcritically fouled membranes, an increase in filtration pressure resulted

360 in a decreased LRV in most instances. For example, with the exception of the LRVs

361 achieved for all the ARB by the F1 membrane in Run 2, both runs showed that the

362 subcritically fouled F2 membranes experienced up to 2-log declines in the LRVs for all

363 three ARB groups when the filtration pressure was increased (Figures 2A to 2C). In both

364 runs, the LRVs achieved by the F2 membranes at the higher filtration pressures (i.e., F2-3

365 and F2-4) were significantly less than the LRVs achieved at the lower filtration pressures

366 (i.e., F2-1 and F2-2) (one-way ANOVA, p < 0.05).

367 In contrast to the subcritically fouled membranes, increasing the filtration pressure

368 applied to the critically fouled F3 membrane did not significantly affect the average LRV

369 of any tested ARB (one-way ANOVA, $\mathrm{p}>0.59$ ).

370 
371 3.7. Foulant layer enhanced the attachment of ARB. The abundance for E. coli PI-7

372 attached per $\mathrm{cm}^{2}$ of the new membrane was $4.92 \times 10^{6}$ in Run 1, which was significantly

373 lower than that of the F1, F2 and F3 membranes (t-test, $\mathrm{p}<0.05$ ) (Figure 3A). In Run 2,

374 the abundance of E. coli PI-7 attached per $\mathrm{cm}^{2}$ of the F1, F2 and F3 membranes was 2.41

$375 \times 10^{7}, 2.40 \times 10^{7}$, and $4.25 \times 10^{7}$, respectively, and these abundances were significantly

376 higher than that on the new membrane by as much as $1-\log$ unit (t-test, $\mathrm{p}=0.01$ ) (Figure

377 3B). Similarly, the abundance of $K$. pneumoniae L7 and E. coli UPEC-RIY -4 attached to

378 the new membrane was significantly lower than that on the F1, F2 and F3 membranes in

379 both runs (t-test, $\mathrm{p}<0.05)$ (Figures $3 \mathrm{~A}$ and $3 \mathrm{~B})$.

380 The interaction between the ARB and the foulant layer was confirmed by ITC (Figure 4).

381 Compared to the blank which did not contain any foulant, the presence of foulant

382 obtained from F1, F2 and F3 membranes released significantly more heat upon

383 interaction with the three ARB (t-test, $\mathrm{p}<0.01$ ). In addition, the heat release was highest

384 when foulant layer obtained from F3 was present. To illustrate, the heat change for F1

385 was $0.035 \mu \mathrm{cal} / \mathrm{s}$ upon interaction with E. coli $\mathrm{PI}-7$, and this value increased by $46.9 \%$

386 and $59.9 \%$ for F2 and F3, respectively, compared to that for F1.

388 3.8. Experiment to verify the LRV for $\boldsymbol{E}$. coli PI-7. To verify the result obtained by 389 qPCR, flow cytometry was applied as an alternative method to assess the LRV and the 390 abundance of the E. coli PI-7 cells adhered to the membrane surfaces (Figure S6). To

391 illustrate, the average, E. coli PI-7 LRV for the new membrane was 5.95 in Run 1 and

3925.19 in Run 2. For F1, the LRV decreased to 2.89 in Run 1 and 3.35 in Run 2. However,

393 the LRV recovered to 3.92 in Run 1 and 4.27 in Run 2 for F3. A further evaluation 
394 regarding the abundance of $E$. coli PI-7 attached to the membrane surfaces revealed

395 higher cell counts on the fouled than on the new membranes (Figure S7). The

396 number $/ \mathrm{cm}^{2}$ of E. coli PI-7 attached to the new membrane was $6.64 \times 10^{4}$ in Run 1 and

$3971.40 \times 10^{5}$ in Run 2 . In contrast, the abundance of E. coli PI-7, measured as the number of

398 bacteria attached per $\mathrm{cm}^{2}$ of fouled membrane (i.e., F1, F2 and F3), ranged from $2.37 \mathrm{x}$

$39910^{6}$ to $1.57 \times 10^{7}$ in Run 1 and from $3.62 \times 10^{6}$ to $3.20 \times 10^{7}$ in Run 2.

400

401

402 4. DISCUSSION

403 The World Health Organization has warned in their 2014 Global Report on Surveillance

404 that "antimicrobial resistance threatens the effective prevention and treatment of an ever-

405 increasing range of infections caused by bacteria, parasites, viruses and fungi" 24 .

406 Because of the widespread use of antibiotics, resistant organisms, including their mobile

407 genetic elements, exist almost ubiquitously in humans, animals, food and the

408 environment. In particular, wastewater has been identified as an important reservoir that

409 can disseminate such resistant organisms and mobile genetic elements into the

410 environment or to end users during reuse events ${ }^{1,25}$. These concerns may impede

411 subsequent effort to reuse treated wastewaters.

413 As such, an effective treatment process is needed to remove ARB and ARGs from

414 wastewater prior to its discharge or reuse. An earlier study assessed the LRVs for these

415 emerging contaminants (i.e., ARB and ARGs) achieved by full-scale aerobic MBRs and

416 determined that the concentrations of ARGs (e.g., tetW, tetO, and sulI) and ARB (e.g., 
417 tetracycline- and sulfonamide-resistant bacteria) in the post-MBR permeate stream were

4181 to $3-\log$ units less than those achieved by activated sludge processes ${ }^{8}$, suggesting that

419 membrane systems are more effective than the conventional activated sludge in removing

420 these emerging contaminants from wastewater. Studies have also been conducted to

421 assess the LRVs for contaminants (e.g., organic micropollutants, bacterial pathogens, and

422 viruses) achieved by anMBRs ${ }^{26-28}$, which in recent years, are proposed as a sustainable

423 alternative to aerobic MBRs for municipal wastewater treatment. For instance, Wei et al.

424 investigated the removal of 15 organic micropollutants by a laboratory-scale anMBR and

425 found $80-92 \%$ rejection rates for most organic micropollutants ${ }^{26}$. Harb et al. further

426 reported that a laboratory-scale anMBR can achieve $>1.7-\log$ removal of opportunistic

427 pathogenic species from municipal wastewater ${ }^{27}$. In addition, Wong et al. reported a 3.7

$428 \log$ removal of coliphages by an anMBR ${ }^{28}$.

430 Nevertheless, most of these existing studies do not evaluate for the removal efficiencies

431 of ARBs and ARGs by anMBRs. In the present study, the LRVs of three plasmids

432 encoding for ARGs ranged from 2.76 to 3.84-log units when the anaerobic membrane

433 became increasingly fouled (Figures 1A and 1C). These reported LRVs approximately

434 match the LRV obtained by Wong and coworkers for viruses ${ }^{28}$. This similarity occurred

435 despite differences between the viruses and plasmids evaluated in the two studies.

436 Viruses such as adenovirus, enterovirus and coliphage have genome sizes that range from

$4373600 \mathrm{nt}$ to $48 \mathrm{kbp}$, depending on whether the virus is a single-stranded RNA virus or a

438 double-stranded DNA virus. These genome sizes would equate to an approximate viral

439 particle diameter of 30 to $100 \mathrm{~nm}$. In comparison, these sizes are much smaller than those 
440 of the plasmids that were evaluated in the present study. The plasmid sequencing did not

441 result in a complete assembly of the plasmids that encode for $b l a_{\mathrm{CTX}-\mathrm{M}-15}$ and $b l a_{\text {OXA-48. }}$.

442 However, the assembled contigs of the partial plasmidic genomes have already revealed a

443 size as large as $110 \mathrm{kbp}$ and $55 \mathrm{kbp}$ for these two plasmids (i.e., $b l a_{\mathrm{CTX}-\mathrm{M}-15}$ and $b l a_{\mathrm{OXA}-48}$ )

444 . Similarly, the IncF plasmid encoding for $b l a_{\mathrm{NDM}-1}$ is reported to have a size as large as

$445110 \mathrm{kbp}^{3}$. Collectively, the plasmids assessed in the current study show comparatively

446 larger genome sizes and are thus likely to have larger particulate sizes compared to

447 viruses. To verify this supposition, the particulate size of all three plasmids used in the

448 current study were further assessed by a dynamic light scattering technique and were

449 found to be ca. 460 to $560 \mathrm{~nm}$ in diameter (Figure S5A).

451 Furthermore, viruses have capsid proteins that are hydrophobic ${ }^{29}$, while extracellular

452 plasmids are generally hydrophilic due to the exposed sugar-phosphate bond of DNA ${ }^{30}$.

453 In the present study, significantly more plasmids were found attached to the fouled

454 compared to the new membranes. This pattern occurred despite no clear correlation

455 between the attachment preference and the surface characteristics. For example,

456 hydrophobicity increases as anaerobic membranes become progressively fouled, and both

457 the membrane surface and the plasmids showed a negative charge (Table 1 and Figure

458 S5B). These conditions would have led to hydrophobic-hydrophilic and charge repulsion

459 between the membrane surfaces and plasmids. However, the abundance of the plasmids

460 that attached to the membranes remained within the same range (Figures 1B and 1D).

461 This effect may have been due to the presence of an electrolyte in the M9 minimal salt

462 medium used during the filtration experiment, which led to a decrease in the repulsion 
463 force exhibited in hydrophobic-hydrophilic and charge interactions ${ }^{31}$. In addition, new

464 membrane exhibits a rougher surface area compared to fouled membranes, which is

465 generally thought to facilitate adhesion ${ }^{32,33}$. Instead, a significantly lower abundance of

466 attached plasmids occurred on the new membranes compared to the fouled ones with

467 relatively smooth surfaces (Figures $1 \mathrm{~B}$ and 1D).

468

469 Despite a lack of understanding regarding the exact mechanisms governing the

470 attachment of plasmids to anaerobic membranes, the presence of foulant improved the

471 removal efficiency for all three of the plasmids. However, the LRVs achieved by

472 membranes fouled to different degrees (i.e., F1, F2, and F3) were similar. This pattern

473 occurred despite an increase in the thickness of the foulant layer (Table 1), suggesting

474 that size exclusion and biovolume are less important factors than adsorption in removing

475 plasmids (Figures 1B and 1D). A higher adsorption of plasmids on the fouled membranes

476 compared to the new membrane was likely due to the higher protein and polysaccharide

477 concentrations measured in the foulant layer of the fouled membranes, which facilitated

478 interaction and the adsorption of the plasmids to the foulant layer. In addition, the

479 presence of a cake layer on the fouled membranes would induce a more severe

480 concentration polarization ${ }^{37}$ than that experienced on the new membrane. Previous

481 studies have shown that concentration polarization improves the rejection of volatile

482 organic compounds, perfluorooctane sulfonates, boron and arsenic ${ }^{34-36}$. Similarly,

483 concentration polarization may have also contributed to the high LRVs for the ARGs

484 achieved by the fouled membranes evaluated in the current study. 
486 Apart from ARG filtration, the current study also investigated the LRVs for three ARB.

487 Prior studies have determined that both E. coli and K. pneumoniae possess a hydrophobic

488 cell surface ${ }^{38,39}$, which would facilitate bacterial attachment to the hydrophobic

489 anaerobic membranes (Figure 3). In addition, the relatively lower negative charge of

490 bacteria compared to plasmids would have resulted in less charge repulsion and thus

491 adsorption onto the membranes (Figure S5B). Although the number of cells attached to

492 the three fouled membranes was significantly higher compared to the new membrane, no

493 significant difference existed among the number of cells attached to the three fouled

494 membranes. This observation implies that other factors (e.g., extracellular polymeric

495 substances, cake layer thickness) and not solely surface properties affect the adhesion of

496 ARB to fouled membranes. To verify this supposition, ITC was used as an alternative

497 method to detect and compare the interaction between the ARB and the foulant layers.

498 Unlike the traditional atomic force microscope (AFM) method, which modifies the AFM

499 tips to detect the interaction force ${ }^{40,41}$, the ITC method measures the heat change that

500 occurs when two molecules interact ${ }^{42}$, which is directly proportional to the level of

501 interaction. When compared to the heat change obtained from the interaction between the

502 bacterial suspensions and the control (i.e., M9 minimal salt medium with no biofilm

503 suspension), more heat was released when the biofilm suspensions obtained from the

504 fouled membranes were injected into the bacterial suspensions (Figure 4). This

505 observation indicates that the ARB can interact with the biofilm matrix, hence accounting

506 for the higher attachment of cells onto the fouled membranes compared to the new one. 
508 The present study further aims to determine whether different filtration pressures applied

509 to these fouled membranes affect their ARB removal efficiencies. The results suggest that

510 when anaerobic membranes are subcritically fouled and the filtration pressure is

511 increased, the removal of ARB is compromised. However, a lower LRV was not

512 observed when the membranes were critically fouled, despite a subsequent increase in

513 filtration pressure.

514

515 The ARB used in this study were found to be of ca. $2000 \mathrm{~nm}$ in particulate size (Figure

516 S5A and Figure S8). Antimicrobial molecules are known for inducing alterations in the

517 bacterial envelope and in its mechanical properties, such as the cell wall elasticity ${ }^{43,44}$.

518 Prior study indicates that the cell wall is an important factor in triggering the passage of

519 bacteria through membranes with a relatively small pore size ${ }^{45-47}$. An earlier study found

520 that antibiotics present in the suspension medium affect the mechanical properties of the

521 bacterial cell wall by decreasing its rigidity, thereby resulting in a greater number of cells

522 passing through a membrane and entering into the permeate stream. However, whether

523 ARB have a higher deformability compared to antibiotic-susceptible bacteria is unknown.

524 Gram-negative bacteria were also demonstrated to cross through membrane barriers by

525 deforming themselves under high filtration pressures of 10 to $950 \mathrm{kPa}^{48,49}$. Earlier study

526 has also shown that the particle size in the cake layer from anaerobic membranes

527 decreases from the top to the bottom layer, resulting in a corresponding decrease in

528 porosity across the different layers ${ }^{50,51}$. This gradual decrease in pore size formed

529 funnel-like structures that would likely facilitate the passage of less rigid cells through

530 membrane pores. Coupled with findings suggesting that an increase in transmembrane 
531 pressure could enlarge membrane pore size $^{52}$, these factors can possibly explain why

532 subcritical fouling would lower the LRV for ARB when the filtration pressure increases.

534 However, the LRVs achieved by the critically fouled membranes returned to a lower

535 level approximating that achieved by the new membranes (Figure 2). This result could be

536 explained by the total blockage of membrane pores via an irremovable foulant layer at

537 that fouling level; therefore, any further increase in the filtration pressure was unable to

538 force deformed cells through the membrane barrier. A total pore blockage is facilitated by

539 the high protein concentration measured in the biofilm matrix of the anaerobic membrane

540 in this study (Figures S4B and S4D) and in an earlier study ${ }^{16}$. These high protein

541 contents may, in turn, contribute significantly to the blockage of anaerobic membrane

542 pores ${ }^{53,54}$.

543

544 In summary, the findings from the present study suggest that as anaerobic membranes

545 fouled progressively, the total LRV for the ARGs increased while that for the ARB

546 initially decreased before subsequently stabilizing at an LRV similar to that of new

547 microfiltration membranes. In particular, for subcritically fouled membranes, a lower

548 LRV for the ARB was attained with an increase in filtration pressure. However, the same

549 compromise in the LRVs was not observed when the membranes were critically fouled.

550 These results collectively suggest that an MBR shows promise in removing at least 2 to

$5513-\log$ units of ARB and ARGs, especially when operated in the long term to favor high

552 removal rates of both $\mathrm{ARB}$ and ARGs.

553 


\section{5. Acknowledgments}

555 The authors would like to thank Mr. Qingtian Guan for providing technical assistance

556 with plasmid assemblies. This study is supported by KAUST Center Competitive

557 Funding FCC/1/1971-06-01 awarded to P.-Y. Hong.

558

\section{Supplementary Information Available}

560 Methods: Growth conditions for antibiotic-resistant bacteria; Plasmid sequencing and

561 assembly; Real-time PCR and detection limit test; Analysis of particulate sizes; Zeta

562 potential analysis.

563 Tables: Matrix of conditions used in this study; Primers and fluorogenic probes for the

564 specific detection of resistance genes.

565 Figures: Schematic diagram of anaerobic membrane reactors and experimental setup for

566 the ARB and ARG filtration experiment; Changes in transmembrane pressure for the

567 different microfiltration membranes; Cross-sectional SEM images of membranes;

568 Concentration of polysaccharides and proteins in soluble EPS; Particulate size and zeta

569 potential of ARB and ARGs; LRV of E. coli PI-7 assessed by flow cytometry;

570 Abundance of E. coli PI-7 attached to membranes assessed by flow cytometry; SEM

571 images of ARB. 
572 Table 1 Roughness, hydrophilicity and surface zeta potential of different membranes. N.A. denotes not applicable.

\begin{tabular}{|c|c|c|c|c|c|c|c|c|}
\hline \multirow[t]{2}{*}{ Membrane } & \multicolumn{2}{|c|}{ Thickness $(\mu \mathrm{m})$} & \multicolumn{2}{|c|}{$\begin{array}{c}\text { Estimated dried } \\
\text { biovolume }\left(\mathrm{mm}^{3}\right)^{\mathrm{a}}\end{array}$} & \multicolumn{2}{|c|}{ Roughness } & \multirow{2}{*}{$\begin{array}{c}\text { Hydrophilicity } \\
\text { Contact angle }\left(^{\circ}\right)\end{array}$} & \multirow{2}{*}{$\begin{array}{c}\begin{array}{c}\text { Surface zeta } \\
\text { potential }\end{array} \\
(\mathrm{mV})\end{array}$} \\
\hline & Run 1 & Run 2 & Run 1 & Run 2 & $\mathrm{R}_{\mathrm{a}}(\mathrm{nm})^{\mathrm{b}}$ & $\mathrm{R}_{\mathrm{q}}(\mathrm{nm})^{\mathrm{c}}$ & & \\
\hline N0 & N.A. & N.A. & N.A. & N.A. & $118.3 \pm 27.0$ & $144.0 \pm 36.0$ & $78.7 \pm 3.8$ & $-44.3 \pm 4.4$ \\
\hline F1 & $2.99 \pm 0.17$ & $3.96 \pm 0.26$ & 15.0 & 19.8 & $79.2 \pm 10.4$ & $102.5 \pm 17.5$ & $90.2 \pm 2.3$ & $-17.3 \pm 0.3$ \\
\hline F2 & $8.80 \pm 0.13$ & $10.4 \pm 0.48$ & 44.0 & 52.2 & $61.7 \pm 6.5$ & $76.1 \pm 7.6$ & $95.5 \pm 1.9$ & $-19.2 \pm 1.9$ \\
\hline F3 & $26.9 \pm 3.24$ & $20.3 \pm 0.43$ & 134 & 102 & $51.1 \pm 6.5$ & $65.2 \pm 8.6$ & $107.4 \pm 1.6$ & $-25.8 \pm 2.3$ \\
\hline
\end{tabular}




\section{FIGURE LEGENDS}

574

575

576

577

578

579

580

581

582

583

584

585

586

587

588

589

590

591

592

593

594

595

596

597

598

599

600

601

602

603

604

605

606

607

608

609

610

611

612

613

614

615

616

617
Figure 1. Log removal value (LRV) and abundance of ARGs attached on membranes. (A) LRV reported in Run 1; (B) Copies of ARGs attached per surface area of membrane in Run 1; (C) LRV reported in Run 2; (D) Copies of ARGs attached per surface area of membrane in Run 2. 0 and $\square$ indicate that the LRV could not be determined because the $b l a_{\mathrm{CTX}-\mathrm{M}-15}$ plasmid and $b l a_{\mathrm{OXA}-48}$ plasmid, respectively, were below the qPCR detection limit for that sample.

Figure 2. ARB log removal value (LRV) of different membranes evaluated by qPCR. (A) LRV for E. coli PI-7 with plasmid encoding bla $a_{\mathrm{NDM}-1}$ in Run 1 and Run 2, (B) LRV for Klebsiella pneumoniae L7 with plasmid encoding bla $a_{\mathrm{CTX}-\mathrm{M}-15}$ in Run 1 and Run 2, (C) LRV for E. coli UPEC-RIY-4 with plasmid encoding bla ${ }_{\text {OXA-48 }}$ in Run 1 and Run 2. (N0: new membrane; N0-1, N0-2, N0-3 and N0-4 denote samples collected at $0 \mathrm{kPa}$. F1 and F2: subcritically fouled membranes harvested at $\sim 20 \mathrm{kPa}$ and $40 \mathrm{kPa}$, respectively; F1-1, F1-2, F1-3 and F1-4 denote samples collected at $5 \mathrm{kPa}, 10 \mathrm{kPa}, 15 \mathrm{kPa}$ and $20 \mathrm{kPa}$, respectively; F2-1, F2-2, F2-3 and F2-4 denote samples collected at $10 \mathrm{kPa}, 20 \mathrm{kPa}, 30$ $\mathrm{kPa}$ and $40 \mathrm{kPa}$, respectively. F3: critically fouled membrane harvested at $\sim 60 \mathrm{kPa} ; \mathrm{F} 3-1$, F3-2, F3-3 and F3-4 denote samples collected at $10 \mathrm{kPa}, 20 \mathrm{kPa}, 40 \mathrm{kPa}$ and $60 \mathrm{kPa}$, respectively. * indicates significant difference.)

Figure 3. Abundance of ARB attached per unit surface area of membrane in (A) Run 1, and (B) Run 2. Abundances were quantified by qPCR. Each type of ARB attached on F1, $\mathrm{F} 2$, and F3 was significantly higher than that attached on new membrane $(\mathrm{p}<0.05)$.

Figure 4. Isothermal titration calorimeter (ITC) results for diluted suspension containing the foulant layer of F1, F2 and F3 membranes with each ARB. The heat change for the foulant layer sampled from F1, F2 and F3 and each ARB was significantly higher than that measured for the control (blank). 


\section{REFERENCES}

1. Rizzo, L.; Manaia, C.; Merlin, C.; Schwartz, T.; Dagot, C.; Ploy, M.; Michael, I.; Fatta-Kassinos, D., Urban wastewater treatment plants as hotspots for antibiotic resistant bacteria and genes spread into the environment: a review. Science of the total environment 2013, 447, 345-360.

2. Pruden, A.; Pei, R.; Storteboom, H.; Carlson, K. H., Antibiotic resistance genes as emerging contaminants: studies in northern Colorado. Environmental Science \& Technology 2006, 40, (23), 7445-7450.

3. Mantilla-Calderon, D.; Jumat, M. R.; Wang, T.; Ganesan, P.; Al-Jassim, N.; Hong, P.-Y., Isolation and characterization of NDM-positive Escherichia coli from municipal wastewater in Jeddah, Saudi Arabia. Antimicrobial agents and chemotherapy 2016, $60,(9), 5223-5231$.

4. Wen, Q.; Tutuka, C.; Keegan, A.; Jin, B., Fate of pathogenic microorganisms and indicators in secondary activated sludge wastewater treatment plants. Journal of environmental management 2009, 90, (3), 1442-1447.

5. Xu, J.; Xu, Y.; Wang, H.; Guo, C.; Qiu, H.; He, Y.; Zhang, Y.; Li, X.; Meng, W., Occurrence of antibiotics and antibiotic resistance genes in a sewage treatment plant and its effluent-receiving river. Chemosphere 2015, 119, 1379-1385.

6. Hirani, Z. M.; DeCarolis, J. F.; Adham, S. S.; Jacangelo, J. G., Peak flux performance and microbial removal by selected membrane bioreactor systems. Water research 2010, 44, (8), 2431-2440.

7. Ottoson, J.; Hansen, A.; Bjorlenius, B.; Norder, H.; Stenstrom, T., Removal of viruses, parasitic protozoa and microbial indicators in conventional and membrane processes in a wastewater pilot plant. Water Research 2006, 40, (7), 1449-1457.

8. Munir, M.; Wong, K.; Xagoraraki, I., Release of antibiotic resistant bacteria and genes in the effluent and biosolids of five wastewater utilities in Michigan. Water research 2011, 45, (2), 681-693.

9. Liao, B.-Q.; Kraemer, J. T.; Bagley, D. M., Anaerobic membrane bioreactors: applications and research directions. Critical Reviews in Environmental Science and

Technology 2006, 36, (6), 489-530.

653 10. Xu, P.; Drewes, J. E.; Kim, T.-U.; Bellona, C.; Amy, G., Effect of membrane

654 fouling on transport of organic contaminants in NF/RO membrane applications.

655 Journal of Membrane Science 2006, 279, (1), 165-175.

656 11. Lim, A.; Bai, R., Membrane fouling and cleaning in microfiltration of activated

657 sludge wastewater. Journal of membrane science 2003, 216, (1), 279-290.

658 12. van den Akker, B.; Trinh, T.; Coleman, H. M.; Stuetz, R. M.; Le-Clech, P.; Khan,

659 S. J., Validation of a full-scale membrane bioreactor and the impact of membrane

660 cleaning on the removal of microbial indicators. Bioresource technology 2014, 155, 661 432-437. 
662 13. Cho, J.; Amy, G.; Pellegrino, J., Membrane filtration of natural organic matter:

663 factors and mechanisms affecting rejection and flux decline with charged

664 ultrafiltration (UF) membrane. Journal of Membrane Science 2000, 164, (1), 89-110.

665 14. Kiso, Y.; Nishimura, Y.; Kitao, T.; Nishimura, K., Rejection properties of non-

666 phenylic pesticides with nanofiltration membranes. Journal of Membrane Science

667 2000, 171, (2), 229-237.

668 15. Wang, F.; Tarabara, V. V., Pore blocking mechanisms during early stages of

669 membrane fouling by colloids. Journal of colloid and interface science 2008, 328, (2),

670 464-469.

671 16. Xiong, Y.; Harb, M.; Hong, P.-Y., Characterization of biofoulants illustrates

672 different membrane fouling mechanisms for aerobic and anaerobic membrane

673 bioreactors. Separation and Purification Technology 2016, 157, 192-202.

674 17. Yun, M.-A.; Yeon, K.-M.; Park, J.-S.; Lee, C.-H.; Chun, J.; Lim, D. J.,

675 Characterization of biofilm structure and its effect on membrane permeability in

676 MBR for dye wastewater treatment. Water research 2006, 40, (1), 45-52.

677 18. Sutisna, B.; Polymeropoulos, G.; Mygiakis, E.; Musteata, V.; Peinemann, K.-V.;

678 Smilgies, D.-M.; Hadjichristidis, N.; Nunes, S. P., Artificial membranes with selective

679 nanochannels for protein transport. Polymer Chemistry 2016, 7, (40), 6189-6201.

680 19. Cheng, H.; Xie, Y.; Villalobos, L. F.; Song, L.; Peinemann, K.-V.; Nunes, S.; Hong,

681 P.-Y., Antibiofilm effect enhanced by modification of 1, 2, 3-triazole and palladium

682 nanoparticles on polysulfone membranes. Scientific reports 2016, 6.

683 20. Mantilla-Calderon, D.; Hong, P.-Y., Fate and persistence of a pathogenic NDM-

684 1-positive Escherichia coli strain in anaerobic and aerobic sludge microcosms.

685 Applied and Environmental Microbiology 2017, AEM. 00640-17.

686 21. Toh, B. E.; Bokhari, O.; Kutbi, A.; Haroon, M. F.; Mantilla Calderon, D.; Zowawi,

687 H.; Hong, P.-Y., Varying occurrence of extended-spectrum beta-lactamase bacteria

688 among three produce types. Journal of Food Safety 2017.

689 22. Al-Jassim, N.; Ansari, M. I.; Harb, M.; Hong, P.-Y., Removal of bacterial

690 contaminants and antibiotic resistance genes by conventional wastewater treatment

691 processes in Saudi Arabia: Is the treated wastewater safe to reuse for agricultural

692 irrigation? Water research 2015, 73, 277-290.

693 23. Timraz, K.; Xiong, Y.; Al Qarni, H.; Hong, P.-Y., Removal of bacterial cells,

694 antibiotic resistance genes and integrase genes by on-site hospital wastewater

695 treatment plants: surveillance of treated hospital effluent quality. Environmental

696 Science: Water Research \& Technology 2017.

697 24. WHO Antimicrobial resistance: global report on surveillance 2014.

698 http://www.who.int/drugresistance/documents/surveillancereport/en/

699 25. Hong, P.-Y.; Al-Jassim, N.; Ansari, M. I.; Mackie, R. I., Environmental and public

700 health implications of water reuse: antibiotics, antibiotic resistant bacteria, and

701

702

703

704

705

706 antibiotic resistance genes. Antibiotics 2013, 2, (3), 367-399.

26. Wei, C.-H.; Hoppe-Jones, C.; Amy, G.; Leiknes, T., Organic micro-pollutants' removal via anaerobic membrane bioreactor with ultrafiltration and nanofiltration. Journal of Water Reuse and Desalination 2016, 6, (3), 362-370.

27. Harb, M.; Hong, P.-Y., Molecular-based detection of potentially pathogenic bacteria in membrane bioreactor (MBR) systems treating municipal wastewater: a 
case study. Environmental science and pollution research international 2017, 24, (6),

708

709

710

711

712

713

714

715

716

717

718

719

720

721

722

723

724

725

726

727

728

729

730

731

732

733

734

735

736

737

738

739

740

741

742

743

744

745

746

747

748

749

750

751
5370.

28. Wong, K.; Xagoraraki, I.; Wallace, J.; Bickert, W.; Srinivasan, S.; Rose, J. B., Removal of viruses and indicators by anaerobic membrane bioreactor treating animal waste. Journal of environmental quality 2009, 38, (4), 1694-1699.

29. Thomas, J. J.; Falk, B.; Fenselau, C.; Jackman, J.; Ezzell, J., Viral characterization by direct analysis of capsid proteins. Analytical chemistry 1998, 70, (18), 38633867.

30. Westhof, E., Water: an integral part of nucleic acid structure. Annual review of biophysics and biophysical chemistry 1988, 17, (1), 125-144.

31. Faghihnejad, A.; Zeng, H., Interaction mechanism between hydrophobic and hydrophilic surfaces: Using polystyrene and mica as a model system. Langmuir 2013, 29, (40), 12443-12451.

32. Pasmore, M.; Todd, P.; Smith, S.; Baker, D.; Silverstein, J.; Coons, D.; Bowman, C. N., Effects of ultrafiltration membrane surface properties on Pseudomonas aeruginosa biofilm initiation for the purpose of reducing biofouling. Journal of Membrane Science 2001, 194, (1), 15-32.

33. Vrijenhoek, E. M.; Hong, S.; Elimelech, M., Influence of membrane surface properties on initial rate of colloidal fouling of reverse osmosis and nanofiltration membranes. Journal of membrane science 2001, 188, (1), 115-128.

34. Baker, R.; Wijmans, J.; Athayde, A.; Daniels, R.; Ly, J.; Le, M., The effect of concentration polarization on the separation of volatile organic compounds from water by pervaporation. Journal of membrane science 1997, 137, (1-2), 159-172. 35. Jin, X.; She, Q.; Ang, X.; Tang, C. Y., Removal of boron and arsenic by forward osmosis membrane: influence of membrane orientation and organic fouling. Journal of membrane science 2012, 389, 182-187.

36. Tang, C. Y.; Fu, Q. S.; Criddle, C. S.; Leckie, J. O., Effect of flux (transmembrane pressure) and membrane properties on fouling and rejection of reverse osmosis and nanofiltration membranes treating perfluorooctane sulfonate containing wastewater. Environmental science \& technology 2007, 41, (6), 2008-2014. 37. Hoek, E. M.; Elimelech, M., Cake-enhanced concentration polarization: a new fouling mechanism for salt-rejecting membranes. Environmental science \& technology 2003, 37, (24), 5581-5588.

38. Di Martino, P.; Cafferini, N.; Joly, B.; Darfeuille-Michaud, A., Klebsiella pneumoniae type 3 pili facilitate adherence and biofilm formation on abiotic surfaces. Research in microbiology 2003, 154, (1), 9-16.

39. Rosenberg, M.; Gutnick, D.; Rosenberg, E., Adherence of bacteria to hydrocarbons: a simple method for measuring cell-surface hydrophobicity. FEMS microbiology letters 1980, 9, (1), 29-33.

40. Lu, R.; Mosiman, D.; Nguyen, T. H., Mechanisms of MS2 bacteriophage removal by fouled ultrafiltration membrane subjected to different cleaning methods. Environmental science \& technology 2013, 47, (23), 13422-13429.

41. Razatos, A.; Ong, Y.-L.; Sharma, M. M.; Georgiou, G., Molecular determinants of bacterial adhesion monitored by atomic force microscopy. Proceedings of the National Academy of Sciences 1998, 95, (19), 11059-11064. 
752 42. Freire, E.; Mayorga, O. L.; Straume, M., Isothermal titration calorimetry.

753 Analytical chemistry 1990, 62, (18), 950A-959A.

754 43. Formosa, C.; Grare, M.; Duval, R. l. E.; Dague, E., Nanoscale effects of

755

756

757 antibiotics on P. aeruginosa. Nanomedicine: Nanotechnology, Biology and Medicine 2012, 8, (1), 12-16.

758 44. Formosa, C.; Grare, M.; Jauvert, E.; Coutable, A.; Regnouf-de-Vains, J.; Mourer, M.; Duval, R.; Dague, E., Nanoscale analysis of the effects of antibiotics and CX1 on a Pseudomonas aeruginosa multidrug-resistant strain. Scientific reports 2012, 2.

760

761

762

45. Lebleu, N.; Roques, C.; Aimar, P.; Causserand, C., Role of the cell-wall structure in the retention of bacteria by microfiltration membranes. Journal of Membrane Science 2009, 326, (1), 178-185.

763

764

765 46. Ghayeni, S. S.; Beatson, P.; Fane, A.; Schneider, R., Bacterial passage through microfiltration membranes in wastewater applications. Journal of Membrane Science 1999, 153, (1), 71-82.

766

767

47. Wang, Y.; Hammes, F.; Duggelin, M.; Egli, T., Influence of size, shape, and

768 flexibility on bacterial passage through micropore membrane filters. Environmental

769 science \& technology 2008, 42, (17), 6749-6754.

770 48. Helling, A.; Kubicka, A.; Schaap, I. A.; Polakovic, M.; Hansmann, B. r.; Thiess,

771

772 H.; Strube, J.; Thom, V., Passage of soft pathogens through microfiltration membranes scales with transmembrane pressure. Journal of Membrane Science 2017, 522, 292-302.

773 49. Gaveau, A.; Coetsier, C. m.; Roques, C.; Bacchin, P.; Dague, E.; Causserand, C.,

774

775

776

777 Bacteria transfer by deformation through microfiltration membrane. Journal of Membrane Science 2017, 523, 446-455.

50. Gao, W.; Lin, H.; Leung, K.; Schraft, H.; Liao, B., Structure of cake layer in a submerged anaerobic membrane bioreactor. Journal of membrane science 2011,

778

779

780 374, (1), 110-120.

51. Xiong, J.; Fu, D.; Singh, R. P.; Ducoste, J. J., Structural characteristics and

781

782

783 development of the cake layer in a dynamic membrane bioreactor. Separation and Purification Technology 2016, 167, 88-96.

52. Arkhangelsky, E.; Gitis, V., Effect of transmembrane pressure on rejection of viruses by ultrafiltration membranes. Separation and Purification Technology 2008, 784 62, (3), 619-628.

785 53. Marti, E.; Monclús, H.; Jofre, J.; Rodriguez-Roda, I.; Comas, J.; Balcázar, J. L., 786 Removal of microbial indicators from municipal wastewater by a membrane 787 bioreactor (MBR). Bioresource technology 2011, 102, (8), 5004-5009.

788 54. Wu, J.; Le-Clech, P.; Stuetz, R. M.; Fane, A. G.; Chen, V., Effects of relaxation and 789 backwashing conditions on fouling in membrane bioreactor. Journal of Membrane 790 Science 2008, 324, (1), 26-32.

791

792

793 

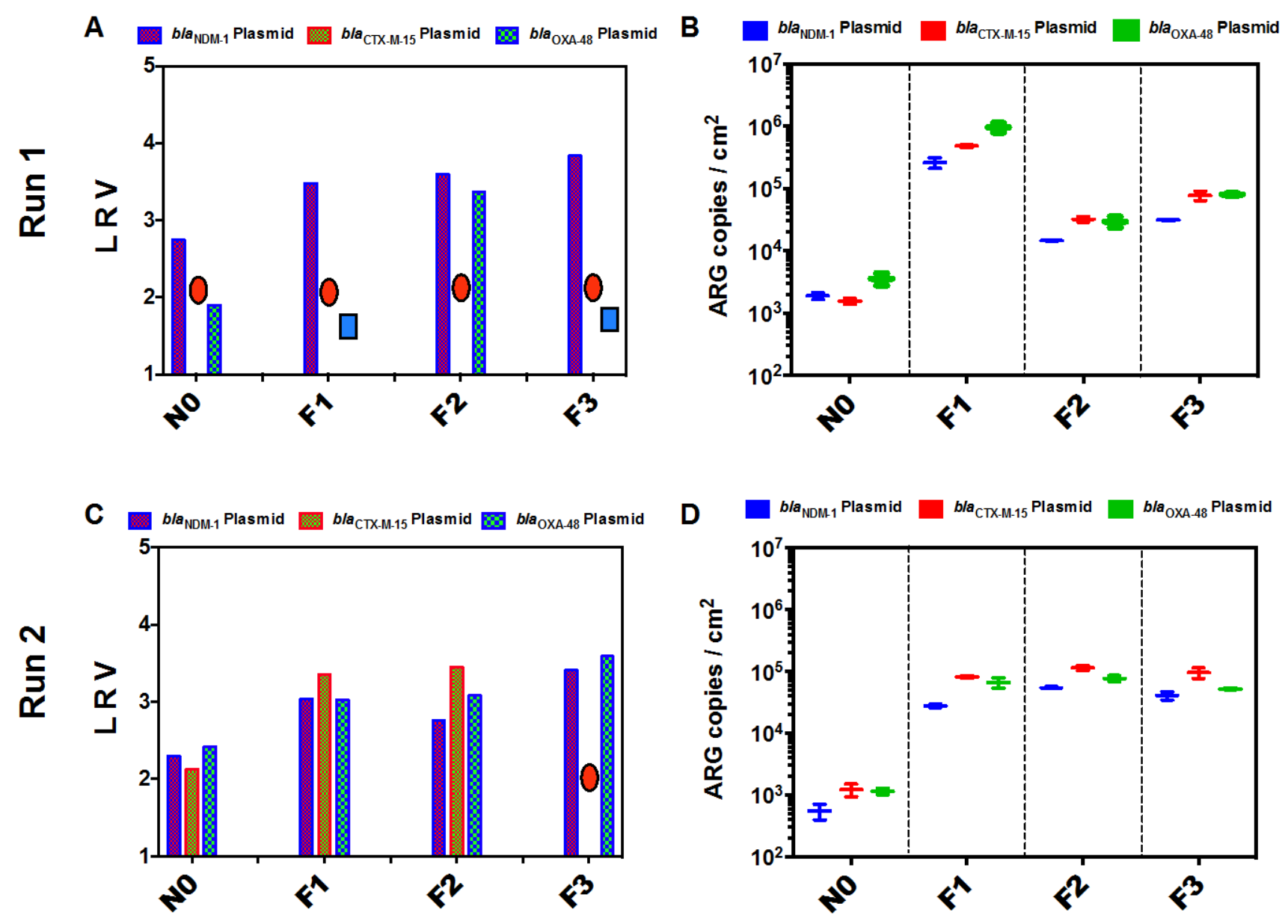

Figure 1. 


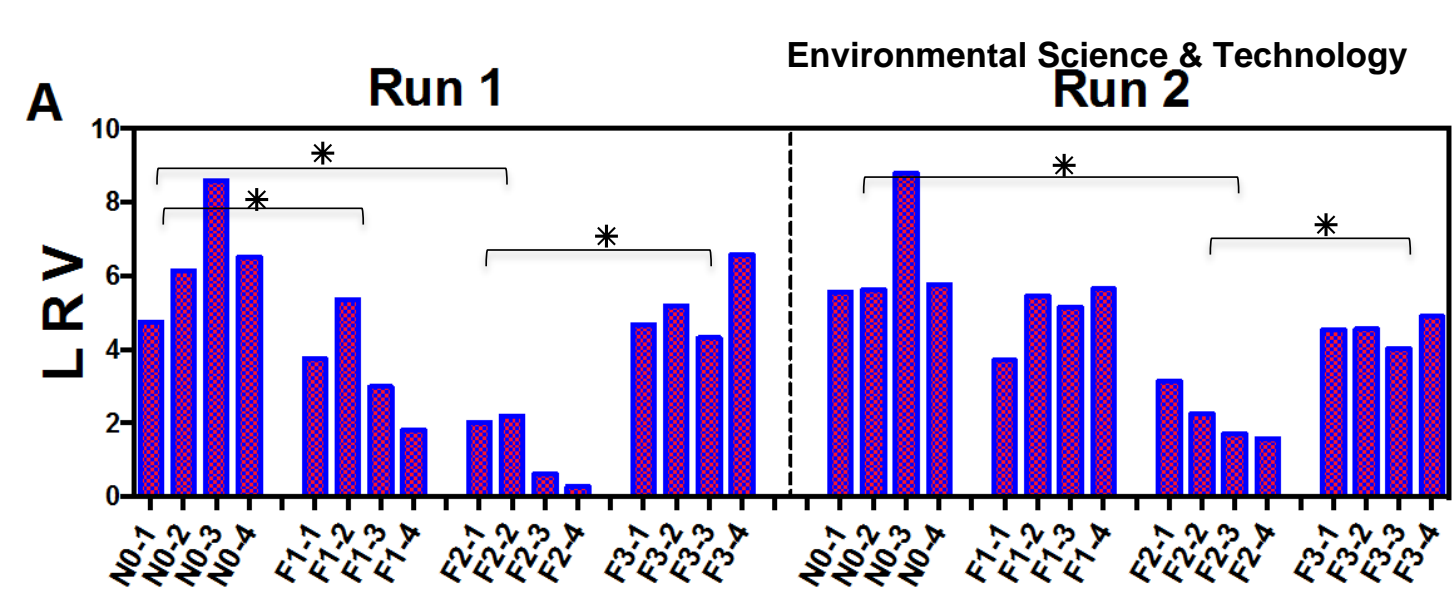

Page 34 of 36

B

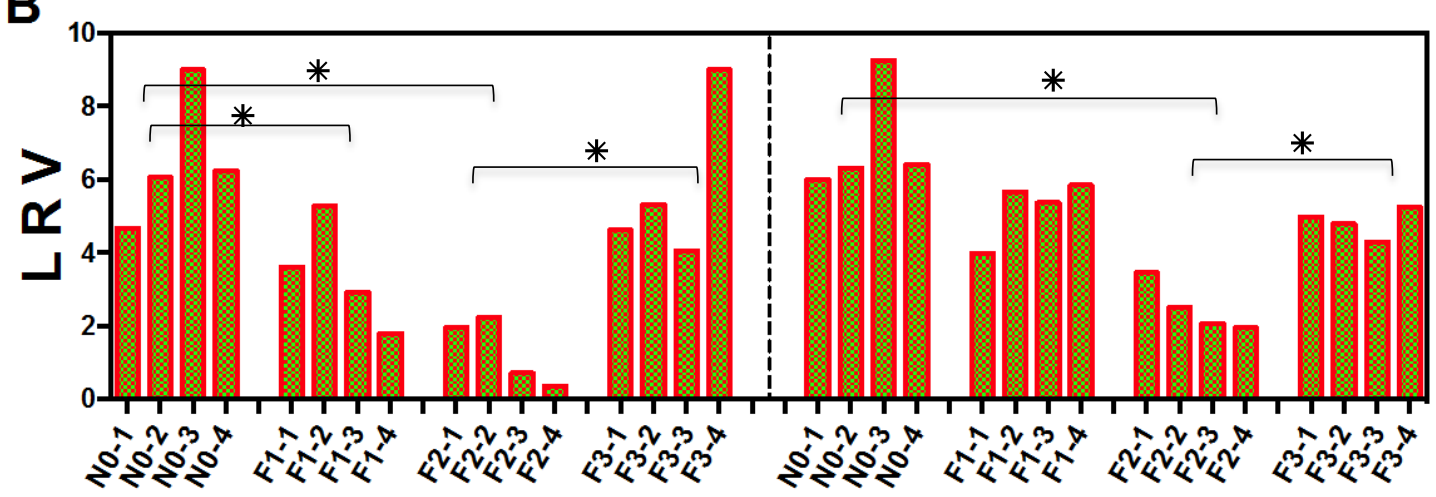

C

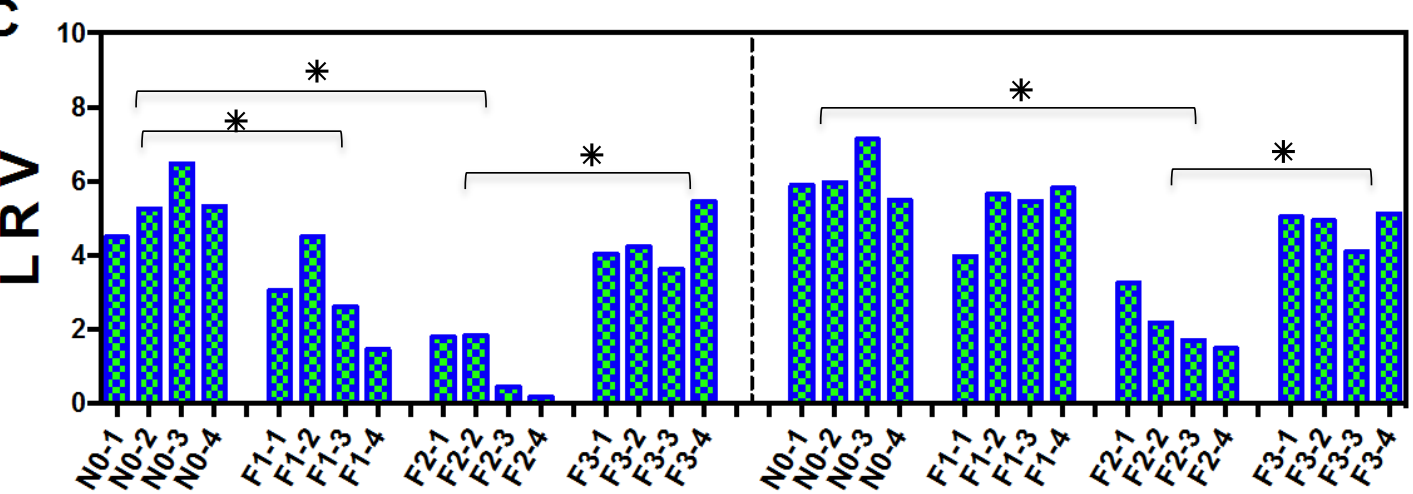

K. pneumoniae L7 with bla $a_{\text {CTX-M-15 }}$

E. coli UPEC-RIY-4 with $b / a_{\mathrm{OXA}-48}$

E. coli PI-7 with bla ${ }_{\mathrm{NDM}-1}$
Figure 2. 
A

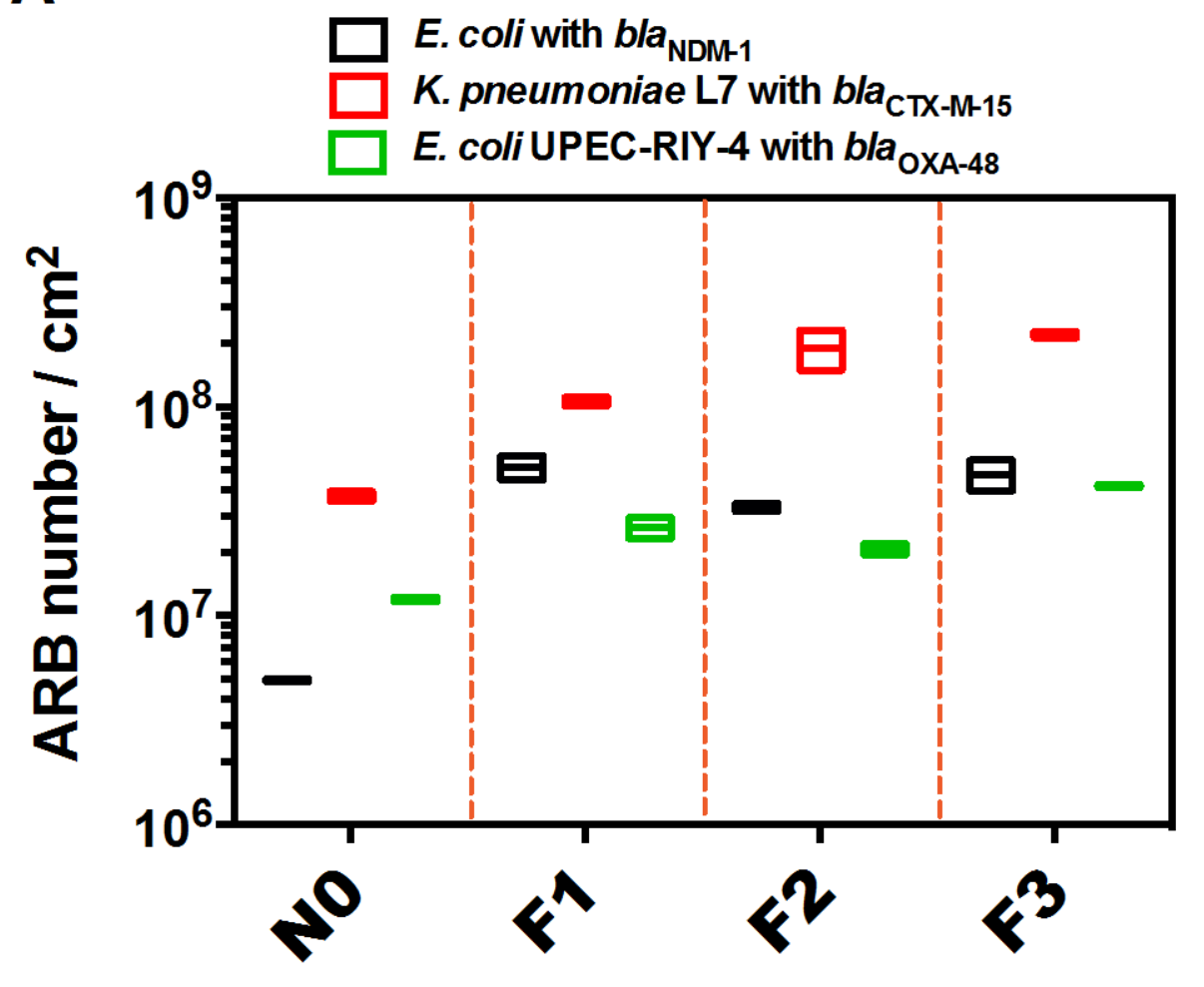

B

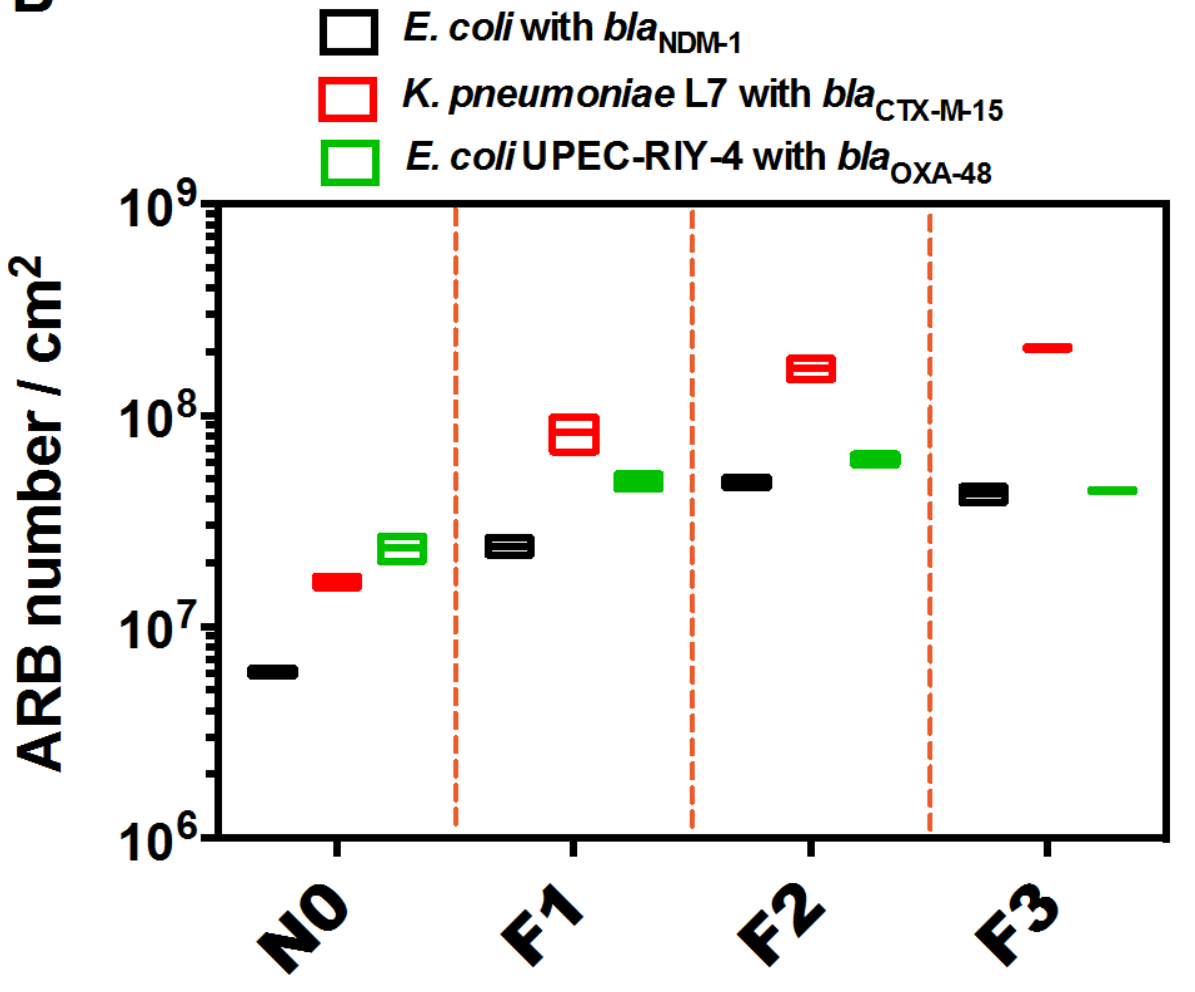

Figure 3. 
- E. coli PI-7 with bla ${ }_{\mathrm{NDM}-1}$

- K. pneumoniae L7 with bla $a_{\mathrm{CTX}-\mathrm{M}-15}$

- E. coli UPEC-RIY-4 with bla OXA-48

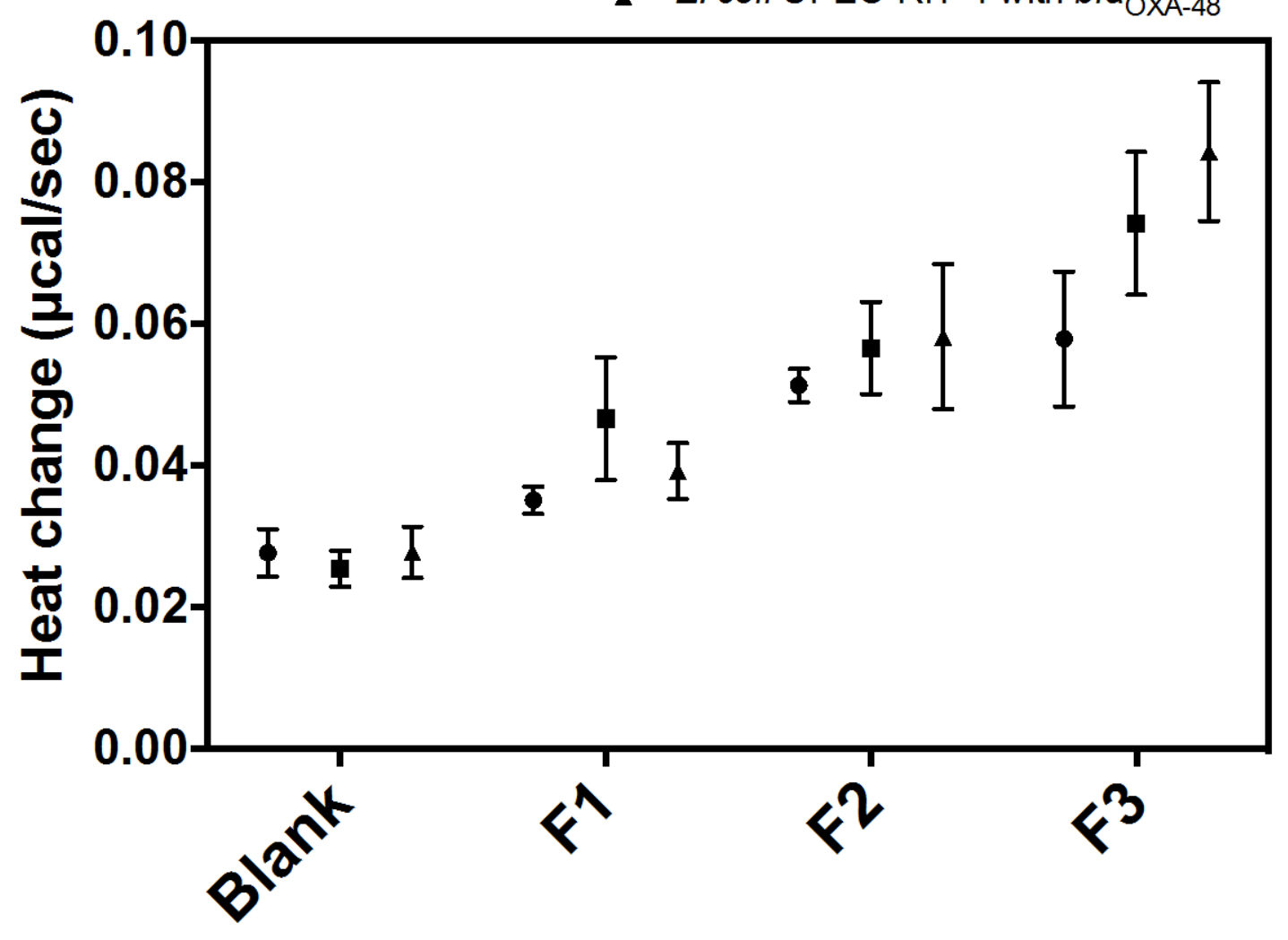

Figure 4. 